\title{
A positive correlation between GC content and growth temperature in prokaryotes
}

\author{
En-Ze Hư ${ }^{\dagger}$ Xin-Ran Lan ${ }^{\dagger}$, Zhi-Ling Liu, Jie Gao and Deng-Ke Niu*
}

\begin{abstract}
Background: GC pairs are generally more stable than AT pairs; GC-rich genomes were proposed to be more adapted to high temperatures than AT-rich genomes. Previous studies consistently showed positive correlations between growth temperature and the GC contents of structural RNA genes. However, for the whole genome sequences and the silent sites of the codons in protein-coding genes, the relationship between GC content and growth temperature is in a long-lasting debate.

Results: With a dataset much larger than previous studies (681 bacteria and 155 archaea with completely assembled genomes), our phylogenetic comparative analyses showed positive correlations between optimal growth temperature (Topt) and GC content both in bacterial and archaeal structural RNA genes and in bacterial whole genome sequences, chromosomal sequences, plasmid sequences, core genes, and accessory genes. However, in the 155 archaea, we did not observe a significant positive correlation of Topt with whole-genome GC content ( $\mathrm{GC}_{w}$ ) or GC content at four-fold degenerate sites. We randomly drew 155 samples from the 681 bacteria for 1000 rounds. In most cases (>95\%), the positive correlations between Topt and genomic GC contents became statistically nonsignificant $(P>0.05)$. This result suggested that the small sample sizes might account for the lack of positive correlations between growth temperature and genomic GC content in the 155 archaea and the bacterial samples of previous studies. Comparing the GC content among four categories (psychrophiles/psychrotrophiles, mesophiles, thermophiles, and hyperthermophiles) also revealed a positive correlation between $\mathrm{GC}_{\mathrm{w}}$ and growth temperature in bacteria. By including the $\mathrm{GC}_{w}$ of incompletely assembled genomes, we expanded the sample size of archaea to 303 . Positive correlations between $\mathrm{GC}_{\mathrm{w}}$ and Topt appear especially after excluding the halophilic archaea whose $\mathrm{GC}$ contents might be strongly shaped by intense UV radiation.
\end{abstract}

Conclusions: This study explains the previous contradictory observations and ends a long debate. Prokaryotes growing in high temperatures have higher GC contents. Thermal adaptation is one possible explanation for the positive association. Meanwhile, we propose that the elevated efficiency of DNA repair in response to heat mutagenesis might have the by-product of increasing GC content like that happens in intracellular symbionts and marine bacterioplankton.

Keywords: GC content, Optimal growth temperature, Prokaryotes, Evolution, Thermophile

*Correspondence: dkniu@bnu.edu.cn; dengkeniu@hotmail.com ${ }^{\dagger}$ En-Ze Hu and Xin-Ran Lan contributed equally to this work. MOE Key Laboratory for Biodiversity Science and Ecological Engineering and Beijing Key Laboratory of Gene Resource and Molecular Development, College of Life Sciences, Beijing Normal University, Beijing 100875, China

\begin{abstract}
Background
As guanine $(G)$ strictly pairs with cytosine $(C)$ and adenine (A) pairs with thymine (T) in DNA double helix, the amount of $\mathrm{G}$ is equal to $\mathrm{C}$, and that of $\mathrm{A}$ is equal to $\mathrm{T}$ in the genomes of any cellular organisms. GC content, i.e., the percentage of $\mathrm{G}+\mathrm{C}$, is widely used to measure genomic nucleotide composition. It is a highly variable
\end{abstract}

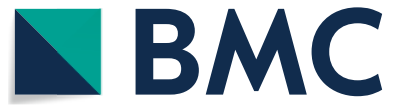
permits use, sharing, adaptation, distribution and reproduction in any medium or format, as long as you give appropriate credit to the original author(s) and the source, provide a link to the Creative Commons licence, and indicate if changes were made. The images or other third party material in this article are included in the article's Creative Commons licence, unless indicated otherwise in a credit line to the material. If material is not included in the article's Creative Commons licence and your intended use is not permitted by statutory regulation or exceeds the permitted use, you will need to obtain permission directly from the copyright holder. To view a copy of this licence, visit http://creativecommons.org/licenses/by/4.0/. The Creative Commons Public Domain Dedication waiver (http://creativeco mmons.org/publicdomain/zero/1.0/) applies to the data made available in this article, unless otherwise stated in a credit line to the data. 
trait ranging from 8 to $75 \%[1-3]$. This genomic trait has been widely studied, and its evolution has been proposed to be associated with numerous mutational and selective forces driven by genetic, metabolic, and ecological factors [4-19]. The high temperature might be the most longdebating [20-22]. Because G:C pairs have an additional hydrogen bond than A:T pairs, the GC-rich genomes are expected to be thermally more stable in high-temperature environments [23]. Bernardi and Bernardi [24] proposed that high GC content is a thermal adaptation of warm-blooded animals.

As prokaryotes have a much wider thermal distribution than plants and animals, bacterial and archaeal genomes are the best materials to test the thermal adaptation hypothesis. An analysis of 764 prokaryotic species, including mesophilic genera and thermophilic genera, did not find a correlation between wholegenome $\mathrm{GC}$ content $\left(\mathrm{GC}_{\mathrm{w}}\right)$ and the optimal growth temperature (Topt) [22]. However, this study found a significant positive correlation between Topt and the GC content of structural RNAs (tRNAs and rRNAs). The rationale of these observations is that the secondary structures of tRNAs and rRNAs are more sensitive to high temperatures than the double-strand helix of DNA. In most prokaryotes, protein-coding genes take most of the genome size. Protein structures and functions constrain the GC content evolution at the nonsynonymous sites of the codons. This functional constraint might conceal the hypothetical thermal adaptation. Compared with $\mathrm{GC}_{\mathrm{w}}$, the $\mathrm{GC}$ content at the third site of the codons $\left(\mathrm{GC}_{3}\right)$ is more desirable to test the thermal adaptation hypothesis. Early solitary cases indicated that $\mathrm{GC}_{3}$ might be related to growth temperature. For example, the tyrosy1-tRNA synthetase gene isolated from the thermophile Bacillus stearothermophilus (current name: Geobacillus stearothermophilus) has a higher $\mathrm{GC}_{3}$ than the homologous gene in Escherichia coli, $68.0 \%$ vs. $59.4 \%$ [25]. The leuB gene isolated from the extreme thermophile Thermus thermophilus HB8 has an extremely high $\mathrm{GC}_{3}, 89.4 \%$ [26]. Hurst and Merchant examined the relationship between $\mathrm{GC}_{3}$ and Topt of 29 archaeal species and 72 bacterial species for a general conclusion [27]. They did not find significant correlations between Topt and $\mathrm{GC}_{3}$ or Topt and $\mathrm{GC}_{\mathrm{w}}$. At the same time, they also found a significant positive correlation between the GC content of structural RNAs and the Topt in both archaea and bacteria. Their analysis accounted for the effect of shared ancestry, so they provided more robust evidence against the thermal adaptation hypothesis. Soon afterward, Xia et al. [28] showed that the growth at increasing temperature (from $37^{\circ} \mathrm{C}$ to $45^{\circ} \mathrm{C}$ ) for 14,400 generations did not increase but decreased the genomic GC content of the bacterium Pasteurella multocida. Furthermore, Lambros et al. [29] reported a negative correlation between optimal growth temperature and the GC content of protein-coding genes in 550 prokaryotes. As the effect of the shared ancestry had not been controlled in their study, we must be cautious in response to their results because the potential nonindependence among their data might violate the basic assumption of the statistical models used in their study.

Subsequently, Musto et al. [30] published a debateprovoking study. As many environmental factors likely influence genomic GC content evolution, closely related species are expected to differ in fewer environmental factors than distantly related species. The correlation of GC content with growth temperature is less likely disturbed by other factors when the analysis is limited within closely related species. Therefore, Musto et al. [30] examined the relationship between genomic GC content and Topt with each prokaryotic family. Among the 20 families they studied, the number of families with positive correlations is significantly higher than expected by chance, no matter the effect of the common ancestors was accounted for or not. Meanwhile, they observed a significant positive correlation when considering all independent contrasts from different families together. However, Marashi and Ghalanbor [31] noticed that most of the significant correlations within each family depend heavily on the presence of a few outlier species. Exclusion of only one species would lead to loss of significant correlations in several families. Basak et al. [32] pointed out that the correlation is sensitive to the presence or absence of a few outliers in some families because the sample sizes in these families were too small. Using non-parametric correlation analysis that is not sensitive to the presence of outliers, Musto et al. [33] repeated their analysis and confirmed their previous results. The debate did not end after that. Wang et al. [34] updated the Topt values for some species and found that the positive correlation between Topt and genomic GC content in two families disappeared. Besides, they suggested that the positive correlation between Topt and genomic GC content in the family Enterobacteriaceae should be explained by the correlation between genome size and optimal growth temperature. Still, this study did not shake the confidence of Musto et al. [35] on the correlation between Topt and genomic GC content in prokaryotes. Although Musto and coauthors have rebutted all the criticisms, their studies have not convinced later authors of review articles [4, 20, 36]. For example, Agashe and Shankar [4] claimed that "it seems unlikely that genomic GC content is driven by thermal adaptation" after reviewing the results of Hurst and Merchant [27] and Xia et al. [28], but without mentioning the debate on Musto et al. [30]. 
As prokaryotic genomes often have many accessory genes frequently lost and gained, the genome-wide measures of GC content could roughly reflect the shaping effects of environmental factors in evolution. By contrast, the structural RNA genes ubiquitously exist in prokaryotic genomes, and their GC contents are more comparable in large-scale phylogenetic analyses. Similarly, the core genome or strictly defined orthologous genes could also accurately reflect the historical shaping effect of growth temperature on GC content evolution. Ream et al. [37] analyzed the GC contents of two genes (ldh- $a$ and $\alpha$-actin) across 51 vertebrate species with adaptation temperatures ranging from $-1.86^{\circ} \mathrm{C}$ to approximately $45^{\circ} \mathrm{C}$. They did not find any significant positive correlations between living temperature and GC content, whether the GC content is measured by the entire sequences, the third codon position, or the fourfold degenerate sites. However, Zheng and Wu [38] found a positive correlation between growth temperature and the GC content in the coding regions of four genes across 815 prokaryotic species, including mesophiles, thermophiles, and hyperthermophiles. These four genes shared by all the 815 prokaryotic genomes could be considered strictly defined core genomes.

Using a manually collected dataset of growth temperature and without accounting for the effect of the common ancestors, Sato et al. [39] recently confirmed the results of Galtier and Lobry [22]. It should be noted that the correlation between Topt and the GC content of structural RNA was consistently observed in much more studies than those mentioned above [19, 39-43]. By contrast, as reviewed above, the correlation between Topt and genomic GC content, if it exists, depends heavily on the sample size, the families of prokaryotes, the sequences, and the methods used to detect it.

Benefitting from the manually curated growth temperature dataset from the database TEMPURA [39], we comprehensively analyzed the relationship between growth temperature and GC content. The present study covers three indexes of growth temperature (maximal growth temperature [Tmax], Topt, and minimal growth temperature [Tmin]) and a series of GC content indexes, including $\mathrm{GC}_{\mathrm{w}}, \mathrm{GC}$ content of the protein-coding sequences $\left(\mathrm{GC}_{\mathrm{p}}\right), \mathrm{GC}$ content at fourfold degenerate sites $\left(\mathrm{GC}_{4}\right), \mathrm{GC}$ content of the genes coding structural RNAs (tRNA, $\mathrm{GC}_{\mathrm{tRNA}}$; $5 \mathrm{~S}$ rRNA, $\mathrm{GC}_{5 \mathrm{~S}}$; $16 \mathrm{~S}$ rRNA, $\mathrm{GC}_{165}$; $23 \mathrm{~S}$ rRNA, $G_{23 S}$ ) and $\mathrm{GC}$ content of non-coding DNA $\left(\mathrm{GC}_{\text {non }}\right.$, including intergenic sequences and untranslated regions of mRNA that are generally unannotated in prokaryotic genomes). The whole genome, primary chromosome sequences, plasmid sequences, core genes, and accessory genes have been examined separately. Our results support a positive correlation between genomic $\mathrm{GC}$ content and growth temperature in bacteria and likely in archaea.

\section{Results \\ Strong phylogenetic signals in both GC contents and growth temperatures}

A significant force shaping prokaryotic evolution is horizontal gene transfer, making the genealogical relationships among bacteria and archaea exhibit a somewhat network-like structure. If bifurcation is not the phylogeny's dominant pattern, most phylogenetic comparative methods are not necessary for prokaryotic evolutionary studies. We are unsure how much this impression has influenced the researchers in prokaryotic genomic studies, but many papers did not use any phylogenetic comparative methods. Despite the frequent horizontal gene transfers, careful examination of the prokaryotic phylogeny could see a statistical tree [44-46]. In principle, the necessity of phylogenetic comparative methods depends on the significance of the phylogenetic signal, a measure of the correlation between the evolution of the analyzed trait and the presumed phylogenetic tree. We first measured the phylogenetic signals of the analyzed traits for the 681 bacteria and 155 archaea obtained from the database TEMPURA [39]. As shown in Table 1 and Additional file 1: Tables S1-S4, all the $\lambda$ values are close to one, which indicates that simple statistical analysis that does not account for common ancestry's effect would lead to inaccurate results $[47,48]$.

\section{Bacterial but not archaeal GC contents correlated with growth temperatures}

We used the phylogenetic generalized least squares (PGLS) regression to examine the relationships between GC contents and growth temperatures. The significant positive and negative slopes of the regressions correspond to significant positive and negative correlations, respectively. The slope value represents the phylogenetically corrected rate of change in GC content as growth temperature changes. Four phylogenetic models, the Brownian motion model (BM), the Ornstein-Uhlenbeck model with an ancestral state to be estimated at the root, the Pagel's lambda model, and the early burst model, have been applied in the analysis. Their results are qualitatively identical and quantitatively similar. As the four models lead to the same conclusion, the trivial differences among their results are unrelated to understanding the relationship between GC content and growth temperature. We present the BM model results in the main text and deposit other models' results as Additional file 1: Tables S5-S7. 
Table 1 The phylogenetic signals of the variables analyzed in this study

\begin{tabular}{|c|c|c|c|c|c|c|}
\hline & Bacteria & & & Archaea & & \\
\hline Traits & $n$ & Pagel's $\lambda$ & P & $n$ & Pagel's $\lambda$ & $P$ \\
\hline Tmax & 681 & 0.957 & $3.5 \times 10^{-178}$ & 155 & 1.000 & $1.5 \times 10^{-72}$ \\
\hline Topt & 681 & 0.950 & $1.1 \times 10^{-196}$ & 155 & 0.988 & $5.7 \times 10^{-70}$ \\
\hline Tmin & 681 & 0.933 & $6.6 \times 10^{-152}$ & 155 & 0.966 & $1.9 \times 10^{-53}$ \\
\hline$G C_{w}$ & 681 & 1.000 & $2.6 \times 10^{-294}$ & 155 & 1.000 & $5.8 \times 10^{-60}$ \\
\hline $\mathrm{GC}_{\mathrm{p}}$ & 681 & 1.000 & $4.7 \times 10^{-292}$ & 155 & 1.000 & $2.4 \times 10^{-59}$ \\
\hline $\mathrm{GC}_{4}$ & 681 & 1.000 & $4.8 \times 10^{-238}$ & 155 & 1.000 & $5.1 \times 10^{-53}$ \\
\hline $\mathrm{GC}_{\text {non }}$ & 681 & 1.000 & $8.6 \times 10^{-305}$ & 155 & 1.000 & $2.0 \times 10^{-65}$ \\
\hline $\mathrm{GC}_{\mathrm{tRNA}}$ & 681 & 0.998 & $6.0 \times 10^{-275}$ & 155 & 1.000 & $2.1 \times 10^{-91}$ \\
\hline $\mathrm{GC}_{5 \mathrm{~S}}$ & 646 & 1.000 & $7.0 \times 10^{-178}$ & 130 & 1.000 & $9.1 \times 10^{-51}$ \\
\hline $\mathrm{GC}_{165}$ & 681 & 0.999 & $8.7 \times 10^{-250}$ & 155 & 0.996 & $3.7 \times 10^{-86}$ \\
\hline $\mathrm{GC}_{23 S}$ & 681 & 1.000 & $2.1 \times 10^{-245}$ & 155 & 1.000 & $6.8 \times 10^{-83}$ \\
\hline
\end{tabular}

Tmax, Topt, and Tmin represent maximal, optimal, and minimal growth temperature, respectively; $\mathrm{GC}_{\mathrm{w},} \mathrm{GC}_{\mathrm{p}}, \mathrm{GC}_{4}, \mathrm{GC}_{\mathrm{tRNA}}, \mathrm{GC}_{55}, \mathrm{GC}_{165}, \mathrm{GC}_{23 s^{\prime}}$, and $\mathrm{GC}_{\text {non }}$ represent the GC contents of the whole genome, the protein-coding sequences, the fourfold degenerate sites, the genes coding tRNAs, the genes coding $5 S$ rRNA, the genes coding $16 \mathrm{~S} \mathrm{rRNA}$, the genes coding $23 \mathrm{~S} \mathrm{rRNA}$, and the non-coding DNA (including intergenic sequences and untranslated regions of mRNA), respectively. The phylogenetic signals of the chromosomal, plasmid, core and accessory genes are also very close to one and deposited in Additional file 1:Tables S1-S4

Interestingly, we also found that Tmax and Topt are positively correlated with various indexes of genomic $\mathrm{GC}$ contents, $\mathrm{GC}_{\mathrm{w}}, \mathrm{GC}_{\mathrm{p}}, \mathrm{GC}_{4}$, and $\mathrm{GC}_{\mathrm{non}}$, in bacteria (Table 2). Nevertheless, bacterial Tmin is not correlated with three GC content indexes (Table 2). In archaea, none of the three temperature indexes (Tmax, Topt, or Tmin) have any significant correlations with any of the four genomic GC content indexes (Table 2).

Consistent with numerous previous studies, we found positive correlations between the $\mathrm{GC}$ contents of structural RNA genes $\left(\mathrm{GC}_{\mathrm{tRNA}}, \mathrm{GC}_{5 \mathrm{~S}}, \mathrm{GC}_{16 \mathrm{~S}}\right.$, and $\left.\mathrm{GC}_{23 \mathrm{~S}}\right)$ and the growth temperatures (Tmax, Topt, and Tmin) in bacteria and archaea (Table 2). The significance values of these correlations are much smaller than the correlations between genomic GC content and growth temperature. Although the correlations between $\mathrm{GC}_{5 \mathrm{~S}}$ and growth temperatures are statistically significant, their significance values are bigger than other structural RNAs. These observations indicate that the strongest correlations between GC content and growth temperatures exist in tRNAs, 16S RNA, and 23S rRNA. We noticed a rank in the slope values, from Tmax, Topt, to Tmin.

If growth temperature could shape GC contents by the stabilities of RNA secondary structures and DNA double helix, a structural RNA or a DNA double helix that is stable at the Tmax or Topt is, of course, stable at the Tmin. This logic makes it reasonable to see that the Tmin has weaker or no significant correlations with GC contents.

The difference in the correlations between bacteria and archaea might be attributed to either unknown intrinsic differences between these two domains or the substantial difference in the sample size, 681 vs. 155 .

\section{Sample sizes matter}

If the lack of significant correlations between genomic DNA and Tmax and Topt in archaea results from the small sample size, the correlations in bacteria would be lost when the sample size of bacteria is reduced to 155. For this reason, we randomly selected 155 bacteria from the 681 bacterial samples for 1000 rounds. The resampling analysis confirmed the idea that the sample sizes matter (Table 3; Additional file 2: Data S1). In $>950$ rounds, the genomic $\mathrm{GC}$ content indexes $\left(\mathrm{GC}_{\mathrm{w}}\right.$, $\mathrm{GC}_{\mathrm{p}}, \mathrm{GC}_{4}$, and $\mathrm{GC}_{\text {non }}$ ) are not correlated with Tmax or Topt $(P>0.05)$. This result could also explain the difference between the present study with Hurst and Merchant [27], which did not find significant correlations between $\mathrm{GC}_{\mathrm{w}} / \mathrm{GC}_{3}$ and Topt by phylogenetic analysis of about 100 prokaryotes. Meanwhile, a few positive correlation cases happen, indicating that significant positive correlations could also be found by chance when the analyzed sample is small.

Besides, the correlations between growth temperature and the GC contents of structural RNA genes might also be lost occasionally when the sample size is severely reduced (Table 3 ). In the 1000 rounds of resampling, lacking significant correlations happens in 308 (for Tmax) and 473 (for Topt) rounds for 5S rRNA genes. However, in the $16 \mathrm{~S}$ and $23 \mathrm{~S}$ rRNA genes, positive correlations were consistently observed in all the 1000 rounds of resampling. We suspected that the tens of times more nucleotides in 16S and 23S rRNA than 5S rRNA make the results of $16 \mathrm{~S}$ and $23 \mathrm{~S}$ rRNAs less sensitive to small sample sizes.

In statistics, the rule of thumb boundary between small and large samples is $n=30$. However, the results 
Table 2 PGLS regression of GC contents and growth temperatures

\begin{tabular}{|c|c|c|c|c|c|c|}
\hline & Bacteria & & & Archaea & & \\
\hline & Slope & $P$ & $P_{\mathrm{BH}}$ & Slope & P & $P_{\mathrm{BH}}$ \\
\hline $\mathrm{GC}_{\mathrm{w}}-\mathrm{Tmax}$ & $7.1 \times 10^{-4}$ & $7.1 \times 10^{-4}$ & $9.4 \times 10^{-4}$ & $6.6 \times 10^{-4}$ & 0.115 & 0.153 \\
\hline $\mathrm{GC}_{\mathrm{w}}-$ Topt & $5.7 \times 10^{-4}$ & 0.009 & 0.011 & $3.3 \times 10^{-4}$ & 0.377 & 0.503 \\
\hline $\mathrm{GC}_{\mathrm{w}}-\mathrm{Tmin}$ & $2.8 \times 10^{-4}$ & 0.156 & 0.226 & $5.2 \times 10^{-4}$ & 0.126 & 0.168 \\
\hline $\mathrm{GC}_{\mathrm{p}}-\mathrm{Tmax}$ & $6.6 \times 10^{-4}$ & 0.002 & 0.002 & $5.6 \times 10^{-4}$ & 0.183 & 0.209 \\
\hline $\mathrm{GC}_{\mathrm{p}}$-Topt & $5.3 \times 10^{-4}$ & 0.015 & 0.016 & $2.4 \times 10^{-4}$ & 0.522 & 0.597 \\
\hline $\mathrm{GC}_{\mathrm{p}}-\mathrm{Tmin}$ & $2.5 \times 10^{-4}$ & 0.202 & 0.231 & $4.6 \times 10^{-4}$ & 0.180 & 0.205 \\
\hline $\mathrm{GC}_{4}-\mathrm{Tm} a x$ & 0.001 & 0.003 & 0.003 & $9.9 \times 10^{-4}$ & 0.321 & 0.321 \\
\hline $\mathrm{GC}_{4}$-Topt & 0.001 & 0.016 & 0.016 & $2.2 \times 10^{-4}$ & 0.806 & 0.806 \\
\hline $\mathrm{GC}_{4}-\mathrm{Tm}$ in & $5.5 \times 10^{-4}$ & 0.239 & 0.239 & $6.9 \times 10^{-4}$ & 0.393 & 0.393 \\
\hline $\mathrm{GC}_{\text {non }}{ }^{-T m a x}$ & $8.0 \times 10^{-4}$ & $1.7 \times 10^{-4}$ & $2.8 \times 10^{-4}$ & $9.1 \times 10^{-4}$ & 0.025 & 0.041 \\
\hline $\mathrm{GC}_{\text {non }}$-Topt & $6.4 \times 10^{-4}$ & 0.004 & 0.006 & $6.4 \times 10^{-4}$ & 0.080 & 0.129 \\
\hline $\mathrm{GC}_{\text {non }}-\mathrm{Tmin}$ & $2.7 \times 10^{-4}$ & 0.170 & 0.226 & $6.5 \times 10^{-4}$ & 0.048 & 0.077 \\
\hline $\mathrm{GC}_{\mathrm{tRNA}}-\mathrm{Tmax}_{\mathrm{max}}$ & $4.1 \times 10^{-4}$ & $2.2 \times 10^{-16}$ & $5.9 \times 10^{-16}$ & $7.1 \times 10^{-4}$ & $1.8 \times 10^{-11}$ & $7.2 \times 10^{-11}$ \\
\hline $\mathrm{GC}_{\mathrm{tRNA}}-{ }^{-T o p t}$ & $3.9 \times 10^{-4}$ & $2.6 \times 10^{-14}$ & $6.9 \times 10^{-14}$ & $5.0 \times 10^{-4}$ & $2.5 \times 10^{-7}$ & $6.7 \times 10^{-7}$ \\
\hline $\mathrm{GC}_{\mathrm{tRNA}}-\mathrm{Tmin}$ & $1.5 \times 10^{-4}$ & $9.1 \times 10^{-4}$ & 0.002 & $4.2 \times 10^{-4}$ & $1.8 \times 10^{-6}$ & $4.7 \times 10^{-6}$ \\
\hline $\mathrm{GC}_{5 \mathrm{~s}^{-} \mathrm{Tmax}}$ & $5.5 \times 10^{-4}$ & $1.2 \times 10^{-6}$ & $2.4 \times 10^{-6}$ & 0.001 & $1.9 \times 10^{-5}$ & $3.9 \times 10^{-5}$ \\
\hline $\mathrm{GC}_{55}$-Topt & $4.4 \times 10^{-4}$ & $1.4 \times 10^{-4}$ & $2.9 \times 10^{-4}$ & $8.9 \times 10^{-4}$ & $1.6 \times 10^{-4}$ & $3.2 \times 10^{-4}$ \\
\hline $\mathrm{GC}_{55^{-}}-\mathrm{Tmin}$ & $3.5 \times 10^{-4}$ & 0.001 & 0.002 & $6.1 \times 10^{-4}$ & 0.005 & 0.010 \\
\hline $\mathrm{GC}_{165}{ }^{-T \max }$ & $5.4 \times 10^{-4}$ & $2.2 \times 10^{-16}$ & $5.9 \times 10^{-16}$ & $8.2 \times 10^{-4}$ & $3.9 \times 10^{-11}$ & $1.0 \times 10^{-10}$ \\
\hline $\mathrm{GC}_{165^{-}}{ }^{\mathrm{Topt}}$ & $5.2 \times 10^{-4}$ & $2.2 \times 10^{-16}$ & $8.8 \times 10^{-16}$ & $7.2 \times 10^{-4}$ & $1.1 \times 10^{-10}$ & $4.5 \times 10^{-10}$ \\
\hline $\mathrm{GC}_{165} \mathrm{~S}^{\mathrm{Tmin}}$ & $4.6 \times 10^{-4}$ & $2.2 \times 10^{-16}$ & $8.8 \times 10^{-16}$ & $5.5 \times 10^{-4}$ & $8.5 \times 10^{-8}$ & $3.4 \times 10^{-7}$ \\
\hline $\mathrm{GC}_{235^{-T m a x}}$ & $6.6 \times 10^{-4}$ & $2.2 \times 10^{-16}$ & $5.9 \times 10^{-16}$ & 0.001 & $2.2 \times 10^{-16}$ & $1.8 \times 10^{-15}$ \\
\hline $\mathrm{GC}_{235^{-T o p t}}$ & $6.5 \times 10^{-4}$ & $2.2 \times 10^{-16}$ & $8.8 \times 10^{-16}$ & 0.001 & $1.2 \times 10^{-14}$ & $9.5 \times 10^{-14}$ \\
\hline $\mathrm{GC}_{235^{-}}-\mathrm{mmin}$ & $4.9 \times 10^{-4}$ & $2.2 \times 10^{-16}$ & $8.8 \times 10^{-16}$ & $8.3 \times 10^{-4}$ & $8.0 \times 10^{-11}$ & $6.4 \times 10^{-10}$ \\
\hline
\end{tabular}

GC contents were the dependent variables, and growth temperatures were the independent variables. The results in this table were obtained using the Brownian motion model. Similar results obtained from three other models are deposited in Additional file 1: Tables S5-S7. $P_{\mathrm{BH}}$, Benjamini-Hochberg adjusted $P$ value. Please see Table 1 for the meanings of the other abbreviations

in Table 3 indicate that $n=155$ is a too-small sample in the phylogenetic comparative analyses of the relationship between growth temperature and genomic GC content. Because of the common ancestor, two closely related lineages with similar growth temperatures and GC contents should be regarded as nearly one effective sample rather than two independent samples. The effective sample size in phylogenetic comparative studies should be much lower than the census number of the analyzed lineages.

\section{Positive correlations observed in genes of both chromosomes and plasmids}

Previous studies showed that plasmids have significantly lower GC contents than chromosomes $[8,49,50]$. Therefore, we examined the correlations between growth temperatures and GC contents separately in chromosomes and plasmids. The separations of plasmids and chromosomes are arbitrary. We strictly followed the classifications of chromosomes and plasmids of the NCBI genome database [51]. Among the 681 bacteria and 155 archaea analyzed above, 172 bacteria and 42 archaea have plasmid genomes. The bacterial chromosomes also have $\mathrm{GC}$ contents $\left(\mathrm{GC}_{\mathrm{w}}, \mathrm{GC}_{\mathrm{p}}, \mathrm{GC}_{4}\right.$, and $\left.\mathrm{GC}_{\text {non }}\right)$ positively correlated with Tmax and Topt (Table 4; Additional file 1: Tables S8-S10). Interestingly, the same pattern was also found in the bacterial plasmids (Table 4) in spite that the correlations of Tmax with $\mathrm{GC}_{4}$ and $\mathrm{GC}_{\text {non }}$ are just significant at marginal levels $(0.05<P<0.1)$. All these correlations are not significant in archaea.

The common ancestor effect was not accounted for in the two previous studies comparing the GC content between plasmids and chromosomes [48, 49]. By the way, we performed a phylogenetic paired t-test [52] and confirmed the pattern of lower GC content in plasmids (Additional file 1: Table S11).

\section{Positive correlations were observed in both core genes and accessory genes}

To correspond to the previous gene-centered studies [38], we examined the correlations in bacterial core genes, i.e., genes present in all the bacteria. The number of core genes decreases rapidly with the increase in the 
Table 3 The appearance of correlations in 1000 rounds of resampling analyses

\begin{tabular}{|c|c|c|c|}
\hline & $\begin{array}{l}\text { Significantly } \\
\text { Negative } \\
(P<0.05)\end{array}$ & $\begin{array}{l}\text { Not Significant } \\
(P>0.05)\end{array}$ & $\begin{array}{l}\text { Significantly } \\
\text { Positive } \\
(P<0.05)\end{array}$ \\
\hline $\mathrm{GC}_{\mathrm{w}}$-Tmax & 0 & 974 & 26 \\
\hline $\mathrm{GC}_{\mathrm{w}}$-Topt & 0 & 991 & 9 \\
\hline $\mathrm{GC}_{\mathrm{p}}$-Tmax & 0 & 976 & 24 \\
\hline $\mathrm{GC}_{\mathrm{p}}$-Topt & 0 & 993 & 7 \\
\hline $\mathrm{GC}_{4}-\mathrm{Tmax}$ & 0 & 962 & 38 \\
\hline $\mathrm{GC}_{4}$-Topt & 0 & 992 & 8 \\
\hline $\mathrm{GC}_{\text {non }}-\mathrm{Tmax}$ & 0 & 974 & 26 \\
\hline $\mathrm{GC}_{\text {non }}$-Topt & 0 & 992 & 8 \\
\hline $\mathrm{GC}_{\mathrm{tRNA}}-\mathrm{Tmax}$ & 0 & 12 & 988 \\
\hline $\mathrm{GC}_{\mathrm{tRNA}}-{ }^{-T o p t}$ & 0 & 21 & 979 \\
\hline $\mathrm{GC}_{55^{-T m a x}}$ & 0 & 308 & 692 \\
\hline $\mathrm{GC}_{55^{-}}$-Topt & 0 & 473 & 527 \\
\hline $\mathrm{GC}_{165}$-Tmax & 0 & 0 & 1000 \\
\hline $\mathrm{GC}_{165}{ }^{-T o p t}$ & 0 & 0 & 1000 \\
\hline $\mathrm{GC}_{235^{-T}}$ Tmax & 0 & 0 & 1000 \\
\hline $\mathrm{GC}_{23 \mathrm{~S}^{-T o p t}}$ & 0 & 0 & 1000 \\
\hline
\end{tabular}

In each round of resampling, 155 samples were randomly drawn from the 681 bacteria. PGLS regression analyses were performed for each round. GC contents were the dependent variables, and growth temperatures were the independent variables. The results in this table were obtained using the Brownian motion model. Please see Table 1 for the meanings of the other abbreviations. The datasets for each round of resampling are deposited in Additional file 2: Data S1

number of analyzed bacterial genomes. With a tradeoff between the number of core genes and the number of bacterial genomes, we selected 28 core genes present in 420 genomes, mostly ribosomal protein genes. Significant positive correlations have been found between $\mathrm{GC}$ contents $\left(\mathrm{GC}_{\mathrm{p}}\right.$ and $\left.\mathrm{GC}_{4}\right)$ and growth temperatures, Tmax, and Topt (Table 5; Additional file 1: Tables S12-S14).
At the opposite side of the core genes, the accessory genes are present in one or a few bacteria. When we define the accessory genes as the genes present in less than $5 \%$ of the analyzed bacterial genomes, on average, each bacterium has 152 accessory genes. Positive correlations were observed between $\mathrm{GC}$ contents $\left(\mathrm{GC}_{\mathrm{p}}\right.$ and $\mathrm{GC}_{4}$ ) and growth temperatures (Tmax and Topt), although the values of significance are slightly larger than those in core genes (Table 5; Additional file 1: Tables S12S14). Similar patterns were observed when we increased the threshold in defining accessory genes to $10 \%(P<0.05$ for all cases).

In addition, we compared the GC content between bacterial core genes and accessory genes using a phylogenetic paired t-test [52]. Unlike the previous analysis of 36 prokaryotes that did not account for the effect of common ancestors [53], we did not observe significant differences in GC content between the core genes and the accessory genes (Additional file 1: Table S15). We also compared the chromosomal accessory genes and plasmid accessory genes. The accessory genes on chromosomes have significantly higher GC contents than those on plasmids (Additional file 1: Table S16).

\section{Qualitative data on growth temperature lead to the same conclusion}

In the ProTraits database and the IMG database [54, 55], many prokaryotes lack quantitative measures of growth temperature but are qualitatively classified into four categories: psychrophiles/psychrotrophiles, mesophiles, thermophiles, and hyperthermophiles. We constructed a qualitative dataset of prokaryote growth temperature, including data downloaded from these two datasets and the prokaryotes in the TEMPURA database classified into the four categories referring reference [39] (Additional file 1: Table S17). We transformed the

Table 4 PGLS regression of GC contents and growth temperatures in chromosomes and plasmids

\begin{tabular}{|c|c|c|c|c|c|c|}
\hline & Plasmid & & & Chromosor & & \\
\hline & Slope & P & $P_{\mathrm{BH}}$ & Slope & P & $P_{\mathrm{BH}}$ \\
\hline $\mathrm{GC}_{\mathrm{w}}-\mathrm{Tmax}$ & 0.001 & 0.009 & 0.043 & $9.6 \times 10^{-4}$ & 0.029 & 0.043 \\
\hline $\mathrm{GC}_{\mathrm{w}}$-Topt & 0.001 & 0.005 & 0.031 & $9.6 \times 10^{-4}$ & 0.023 & 0.031 \\
\hline $\mathrm{GC}_{\mathrm{p}}-\mathrm{Tm} \max$ & 0.001 & 0.016 & 0.043 & $9.1 \times 10^{-4}$ & 0.038 & 0.046 \\
\hline GC -Topt & 0.001 & 0.010 & 0.031 & $9.2 \times 10^{-4}$ & 0.031 & 0.034 \\
\hline $\mathrm{GC}_{4}-\mathrm{Tmax}$ & 0.002 & 0.072 & 0.072 & 0.002 & 0.027 & 0.043 \\
\hline $\mathrm{GC}_{4}$-Topt & 0.002 & 0.044 & 0.044 & 0.002 & 0.017 & 0.031 \\
\hline $\mathrm{GC}_{\text {non }}{ }^{-T m a x}$ & $8.3 \times 10^{-4}$ & 0.055 & 0.060 & 0.001 & 0.021 & 0.043 \\
\hline $\mathrm{GC}_{\text {non }}$-Topt & $9.3 \times 10^{-4}$ & 0.025 & 0.031 & 0.001 & 0.021 & 0.031 \\
\hline
\end{tabular}

GC contents were the dependent variables, and growth temperatures were the independent variables. The results in this table were obtained using the Brownian motion model. Similar results obtained from three other models are deposited in Additional file 1: Tables S8-S10. $P_{B H}$, Benjamini-Hochberg adjusted $P$ value. Please see Table 1 for the meanings of the other abbreviations 
Table 5 PGLS analysis of GC contents and growth temperatures in core genes and accessory genes

\begin{tabular}{|c|c|c|c|c|c|c|}
\hline & \multicolumn{3}{|c|}{ Core Genes } & \multicolumn{3}{|c|}{ Accessory Genes } \\
\hline & Slope & $P$ & $P_{\mathrm{BH}}$ & Slope & $P$ & $P_{\mathrm{BH}}$ \\
\hline $\mathrm{GC}_{\mathrm{p}}-\mathrm{Tmax}$ & $7.6 \times 10^{-4}$ & $9.6 \times 10^{-4}$ & 0.002 & $9.0 \times 10^{-4}$ & 0.001 & 0.002 \\
\hline$G C_{p}$-Topt & $6.4 \times 10^{-4}$ & 0.007 & 0.025 & $6.3 \times 10^{-4}$ & 0.026 & 0.030 \\
\hline $\mathrm{GC}_{4}-\mathrm{Tmax}$ & 0.002 & $6.3 \times 10^{-4}$ & 0.002 & 0.002 & 0.003 & 0.003 \\
\hline $\mathrm{GC}_{4}$-Topt & 0.002 & 0.004 & 0.025 & 0.002 & 0.019 & 0.030 \\
\hline
\end{tabular}

GC contents were the dependent variables, and growth temperatures were the independent variables. The results in this table were obtained using the Brownian motion model. Similar results obtained from three other models are deposited in Additional file 1: Tables S12-S14. $P_{\mathrm{BH}}$, Benjamini-Hochberg adjusted $P$ value. Please see Table 1 for the meanings of the other abbreviations

qualitative characters into numerical values by assigning $1,2,3$, and 4 to the psychrophiles/psychrotrophiles, mesophiles, thermophiles, and hyperthermophiles, respectively. Because only some genomes have been completely assembled, we used their $\mathrm{GC}_{\mathrm{w}}$ values downloaded directly from the NCBI genome database. Using the phylogenetic tree retrieved from the Genome Taxonomy Database [53], we performed PGLS regression analysis using the models mentioned above. The four models gave qualitatively identical results, so we only present the BM model because it has the smallest Akaike information criterion (AIC) value. There is a positive correlation between $\mathrm{GC}_{\mathrm{w}}$ content and growth temperature in bacteria (slope $=0.457, P=0.001$ ), but not in archaea (slope $=-0.582, P=0.170)$. Although this dataset (4696 bacteria and 279 archaea) is much larger than analyzed above (681 bacteria and 155 archaea), it lost much information during the qualitative classification. All the differences in growth temperature within each category disappear.

We also examined whether the contrast in the temperature category is correlated with the contrast in the GC content between terminal tips of the phylogenetic tree. Consulting reference [6], 273 bacterial and 41 archaeal pairs were retrieved from the Genome Taxonomy Database [56]. On average, the bacteria with higher ranks in Topt have $1.43 \%$ more GC than their paired bacteria with lower ranks (Additional file 1: Table S18). Pairwise comparison showed significantly higher GC contents in the bacteria with higher ranks in growth temperature (Wilcoxon signed rank test, $P=0.019$, Fig. 1A). Still, no significant differences were observed between paired archaea with different growth temperature ranks (Wilcoxon signed rank test, $P=0.446$, Fig. $1 \mathrm{~B}$ ).

\section{Evolutionary jumps in bacterial GC contents are correlated with Topt changes}

Mahajan and Agasheand [4] recently found that the Lévy jumps model [57] could explain prokaryotic GC content evolution better than the Brownian model. The
GC content constantly evolves and sometimes experiences discrete changes, i.e., jumps. Following Mahajan and Agasheand [3], we first confirmed that the Lévy jumps model could better explain the $\mathrm{GC}_{\mathrm{w}}$ and Topt in our dataset than the simple Brownian model.

The Lévy jumps model has not been integrated into the PGLS packages. It could not replace the BM model in regression analysis. As an alternate, we retrieved the detected jumps in $\mathrm{GC}_{\mathrm{w}}$ and examined whether significant changes in Topt accompany them. The phylogenetic locations of jumps were inferred using the levolution software [57]. In this procedure, only the posterior probabilities (pp) of the presence of $>0$ jumps were estimated, but the exact number or magnitude of jumps on each branch could not be predicted. In practice, the "precision" of jump inference is negatively correlated with the "recall" of actual jumps. By adjusting the threshold of posterior probabilities of the presence of $>0$ jumps for a precision $>85 \%$, we obtained the $\mathrm{GC}_{\mathrm{w}}$ jumps with $88.5 \%$ precision and an acceptable recall of $37.0 \%$ (Additional file 1: Table S19). As shown in Fig. $2 \mathrm{~A}$, the magnitudes of bacterial $\mathrm{GC}_{\mathrm{w}}$ jumps are positively correlated with the changes in Topt (Spearman's rank correlation, 2-tailed, $n=108$, rho $=0.209$, $P=0.030$ ). When the precision of jump inference was increased to $96.9 \%$, the recall decreased to $21.5 \%$, and no significant correlation was observed in the smaller sample (Spearman's rank correlation, 2-tailed, $n=56$, rho $=0.195, P=0.150$ ).

Meanwhile, we detected the evolutionary jumps in Topt using the same model. By adjusting the threshold of posterior probabilities, we inferred the Topt jumps with $95.3 \%$ precision and $21.5 \%$ recall (Additional file 1: Table S20). A positive correlation was observed between the magnitudes of the jumps in Topt and the changes of GC contents at the positions of Topt jumps (Spearman's rank correlation, 2-tailed, $n=86$, rho $=0.280, P=0.009$, Fig. 2B).

These two correlations indicate that dramatic evolutionary changes in bacterial Topt are statistically 


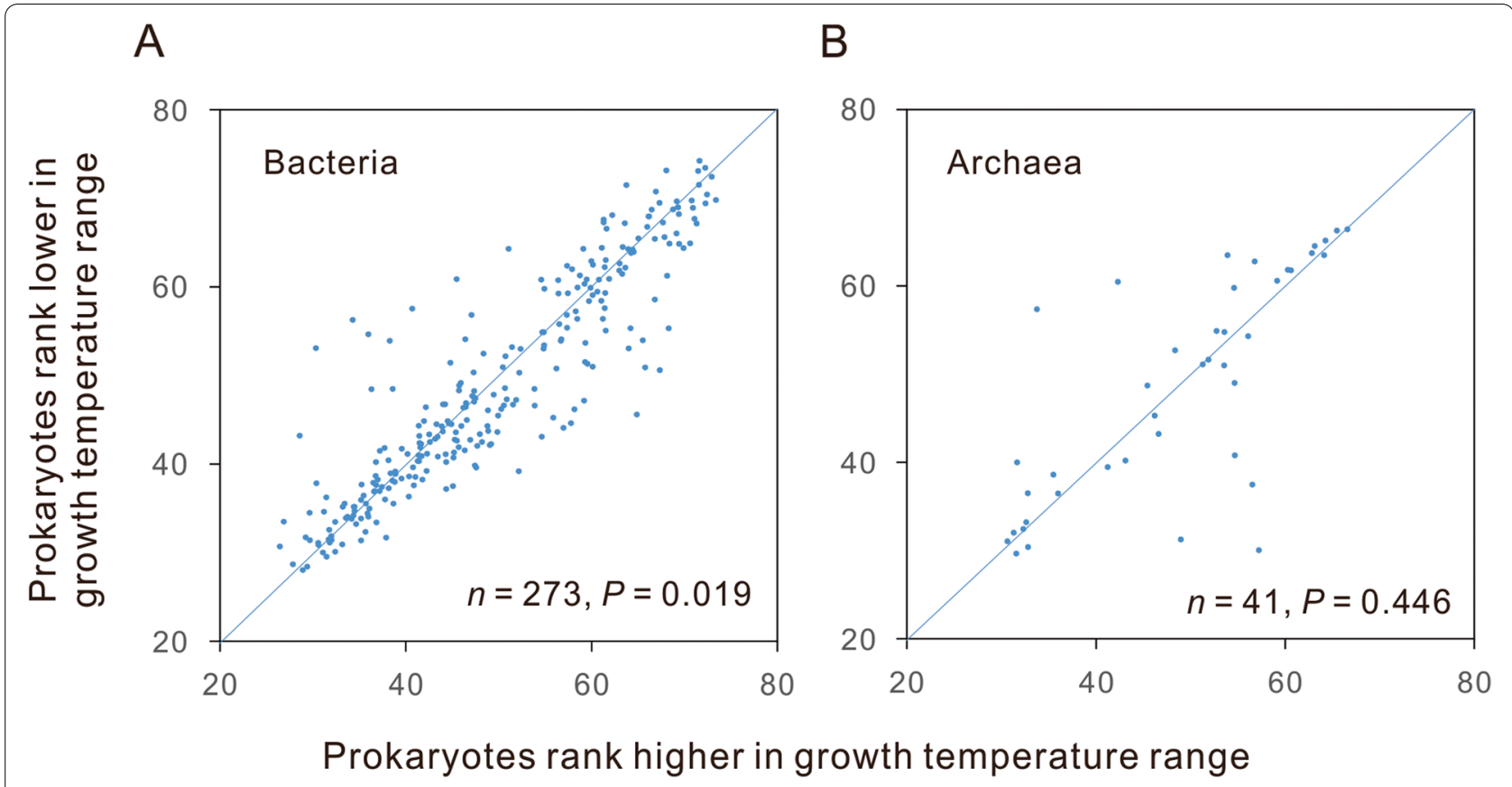

Fig. 1 Pairwise comparison of the GC contents between closely related prokaryotes with different growth temperature ranges. Both bacteria (A) and archaea (B) were classified into four ranks according to their growth temperature, from low to high: psychrophiles/psychrotrophiles, mesophiles, thermophiles, and hyperthermophiles. The diagonal line represents cases in which prokaryotes with different ranks have the same GC contents. Points above the line (153 pairs of bacteria and 17 pairs of archaea) represent cases in which prokaryotes with higher ranks have higher GC contents than their paired relatives, while points below the line (119 pairs of bacteria and 24 pairs of archaea) indicate the reverse. The $p$ values were calculated using two-tailed Wilcoxon signed-rank tests. The exact values of the GC contents are present in Additional file 1:Table S18

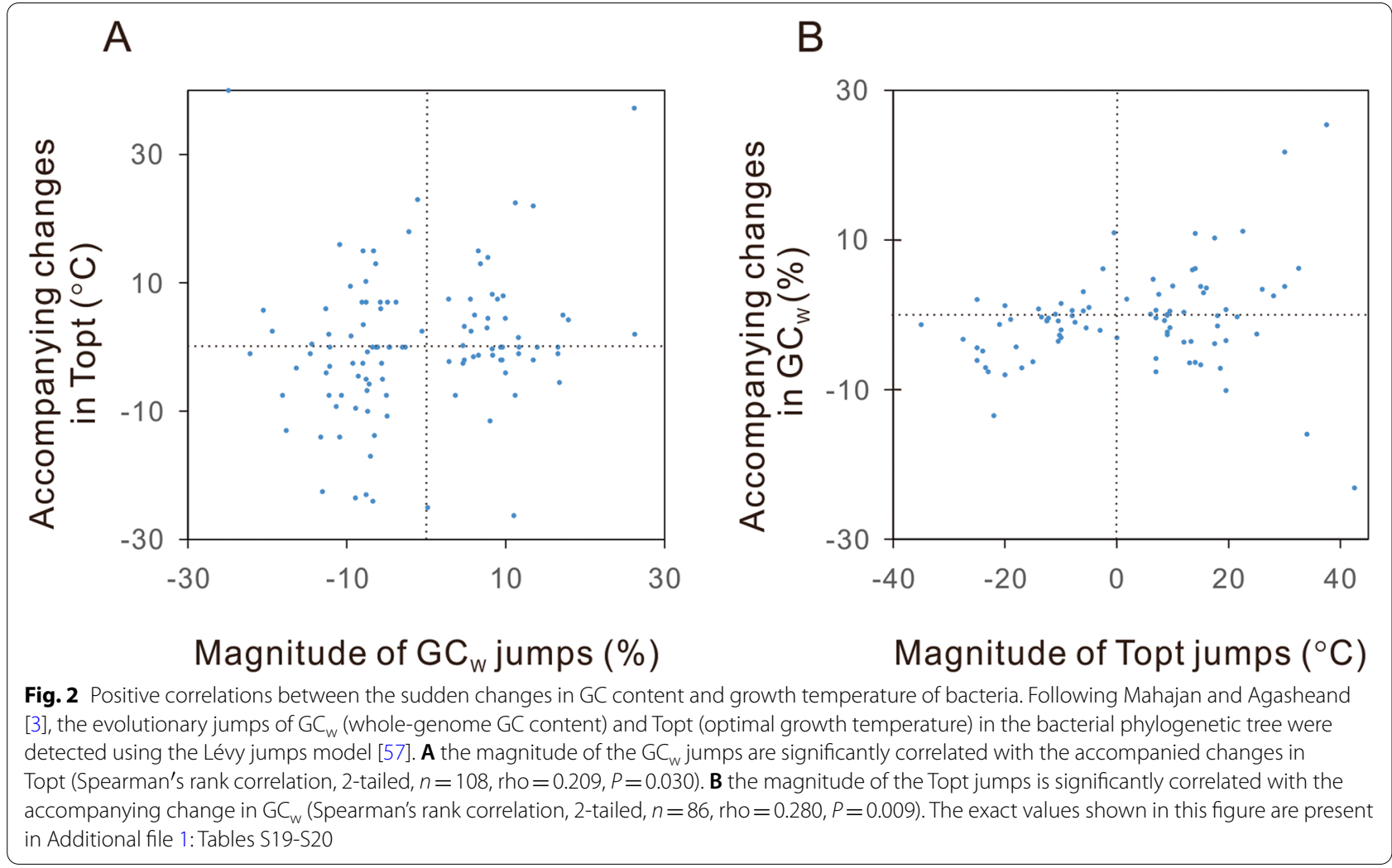


accompanied by changes in GC contents in the same direction and vice versa.

\section{Positive correlation between $\mathrm{GC}_{\mathrm{w}}$ and Topt appears in Archaea after excluding halophiles}

The above resampling analysis indicates that a positive correlation between genomic GC contents and growth temperature might be observed when we have a larger sample of archaea. In bacteria, we found such positive correlations in both chromosomes and plasmids, core and accessory genes. It seems that the positive correlation could be observed in partial sequences of bacterial genomes. For this reason, we expanded the archaeal sample size by including the incompletely assembled genomes.

For the archaea indexed in the database TEMPURA [39], we found 303 species in the All-Species Living Tree [58], a phylogenetic tree constructed using 16S rRNA sequences. These 303 samples include complete genomes and incompletely assembled genomes labeled as chromosome, scaffold, and contig in the NCBI genome database [51]. First, a significant positive correlation was observed between Topt and $\mathrm{GC}_{16 \mathrm{~S}}$ in the present dataset for all the four models we used $\left(P \leq 1.3 \times 10^{-6}\right.$ for all the four cases). Since many genomes of the 303 archaeal samples are not full genome sequences, we did not calculate the $\mathrm{GC}_{\mathrm{p}}, \mathrm{GC}_{4}, \mathrm{GC}_{\text {non }}, \mathrm{GC}_{\mathrm{tRNA}}, \mathrm{GC}_{5 \mathrm{~S}}$, or $\mathrm{GC}_{23 \mathrm{~S}}$. The $\mathrm{GC}_{\mathrm{w}}$ of these 303 archaea were downloaded directly from the database TEMPURA [39]. Four models gave conflicting results on the relationship between $\mathrm{GC}_{\mathrm{w}}$ and Topt. Only Pagel's lambda model showed a positive correlation between $\mathrm{GC}_{\mathrm{w}}$ and Topt (slope $=9 \times 10^{-4}, P=0.02$ ). All the other three models showed significantly negative correlations $\left(P \leq 2.2 \times 10^{-16}\right.$ for all the cases $)$. Pagel's lambda model has the lowest AIC value and thus could be regarded as the model most fitting the data. Despite this, we are not confident in giving a conclusion based on Pagel's lambda model.

By closely examining the scatter diagram, we noticed that Halobacteria have uniquely higher GC contents than other archaea with similar Topt (Fig. 3). The high GC content of Halobacteria was suggested to reduce the chance of thymine dimer formation caused by the intense sunlight UV irradiation [59]. The strong selective force resulting from UV irradiation could overturn the potential effect of their low growth temperatures. For this reason, we examined the relationship between $\mathrm{GC}_{\mathrm{w}}$ and Topt in other archaea. Although the sample size decreased to 152 , the positive correlations could be observed with high confidence. Ornstein-Uhlenbeck and Pagel's lambda models were the first and the second models most fitting the data. They all showed significant positive correlations between $\mathrm{GC}_{\mathrm{w}}$ and Topt (slope $=0.001$ for both cases and $P=0.029$ and 0.046 , respectively). Although the other two models, the BM model and the early burst model, did not show statistically significant correlations $(P=0.08$ and 0.12 , respectively), they presented positive slopes for the phylogenetic regressions $\left(7.8 \times 10^{-4}\right.$ and $\left.6.5 \times 10^{-4}\right)$.

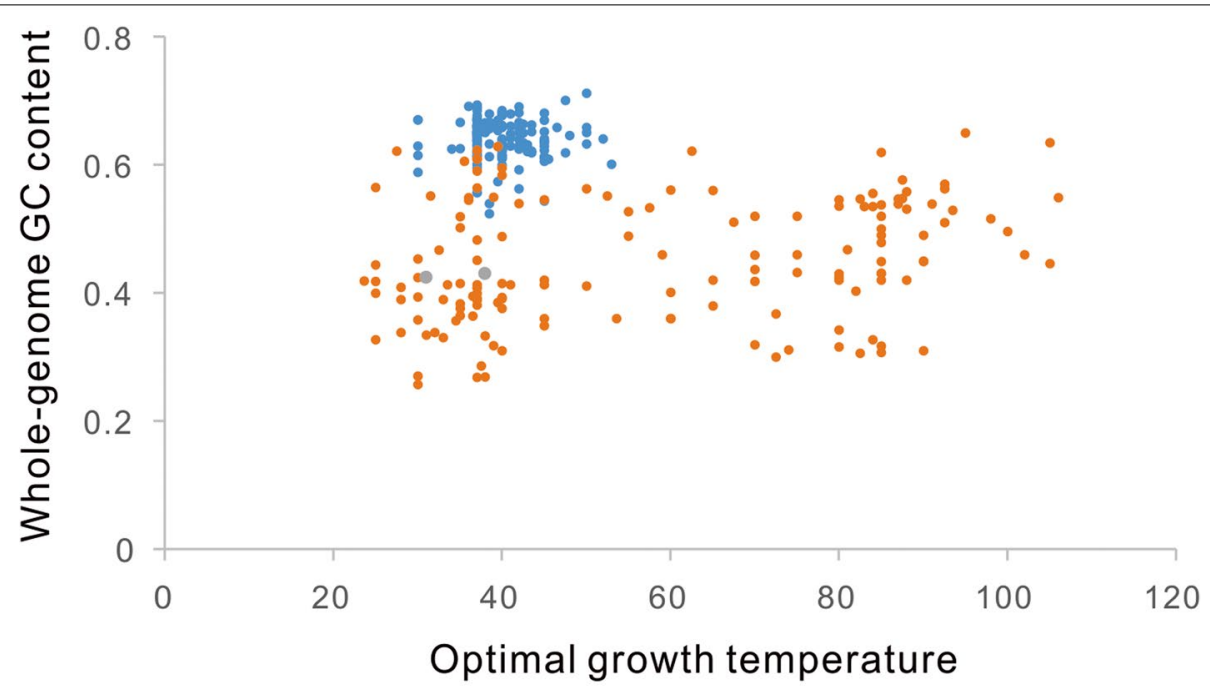

- Halobacteria - Other halophilic archaea - Nonhalophilic archaea

Fig. 3 Relationship between whole-genome $\mathrm{GC}$ content $\left(\mathrm{GC}_{w}\right)$ and optimal growth temperature (Topt) in Archaea. The Topt ranges of Halobacteria $(n=151)$, other halophilic archaea $(n=2)$, and nonhalophilic archaea $(n=150)$ are 30 to $53^{\circ} \mathrm{C}, 31$ to $38^{\circ} \mathrm{C}$, and 23.6 to $106^{\circ} \mathrm{C}$, respectively. Phylogenetic generalized least squares regression analysis using the Ornstein-Uhlenbeck model with an ancestral state to be estimated at the root showed a significant positive correlation between $\mathrm{GC}_{w}$ and Topt in nonhalophilic archaea (slope $=0.001, P=0.025$ ) 
Furthermore, we found two halophilic archaea, Methanocalculus halotolerans and Methanohalophilus halophilus, not belonging to Halobacteria, by consulting the HaloDom database [60]. Excluding these two species further slightly reduced three significance values of the PGLS regression slopes, $P=0.025,0.046,0.064$, and 0.10 for the Ornstein-Uhlenbeck model, the Pagel's lambda model, the BM model (BM), and the early burst model, respectively. It should be noted that the sample size of the non-halophilic archaeal dataset is only 150 . According to our resampling analysis in bacteria, it is a small size with low statistical power.

\section{Nonlinearity in the relationship between Topt and GC contents}

PGLS regression is a method measuring linear correlations. It could just approximately show the general relationship if the correlation between GC content and Topt is nonlinear. The generalized additive mixed model (GAMM) could be used to measure the nonlinear associations across phylogenetic lineages if a low taxonomic level (e.g., species or genus) is adjusted for as a random effect $[61,62]$. By assuming that the species belonging to the same genus have more similar GC contents and growth temperatures than species belonging to different genera, we adjusted for the genus as a random effect. According to the genus names, the 681 bacteria and 155 archaea were divided into 536 groups. The GAMM model could give a value of the effective degrees of freedom (edf), a proxy for the degree of nonlinearity in the relationships between Topt and GC contents. An edf of 1 indicates a linear relationship, whereas a high value $(8 \sim 10$ or higher $)$ indicates high nonlinearity in the relationship [63]. Using the GAMM model, we examined the nonlinear relationships between Topt and GC contents across the 836 prokaryotic genomes. As shown in Fig. $4 \mathrm{~A}$, the relationship between Topt and $\mathrm{GC}_{\mathrm{w}}$ exhibits a moderate level of nonlinearity $\left(\mathrm{edf}=5.3, P=10^{-4}\right.$ ), most likely to have some inflection points like $30^{\circ} \mathrm{C}$ and $70^{\circ} \mathrm{C}$. Similar levels of nonlinearity have been observed in the relationships of Topt with $\mathrm{GC}_{\mathrm{p}}, \mathrm{GC}_{4}, \mathrm{GC}_{\mathrm{tRNA}}$, $\mathrm{GC}_{16 \mathrm{~S}}$, and $\mathrm{GC}_{23 \mathrm{~S}}$ (edf=4.5 6.2, $P<0.001$, Fig. 4B-F and Additional file 3: Fig. S1). The relationship between Topt and $\mathrm{GC}_{5 \mathrm{~S}}$ exhibits a weak nonlinearity $(\mathrm{edf}=1.5$, $P=2 \times 10^{-16}$ ). In spite of the nonlinear correlations, Topt and the GC contents of structural RNA genes exhibit clear positive associations (Fig. 4 and Additional file 3: Fig. S1). The overall trends between Topt and other GC content indexes could not be easily figured out from Fig. 4 and Additional file 3: Fig. S1. We suggest that the above results of PGLS regressions give us the answer.

We also examined the relationships between Topt and GC contents in two subsamples of the 681 bacteria, the highest 30\% Topt species and the lowest 30\% Topt species using PGLS regression. No statistically significant results were obtained ( $P>0.05$ for all the cases). It may be attributed to the smaller sample sizes or the local nonlinearity of the relationship within the analyzed ranges.

\section{Other concerns on the correlation between $\mathrm{GC}_{\mathrm{w}}$ and Topt}

Some previous studies suggest that the stability of DNA double helix depends heavily on the frequency of specific dinucleotides [64-66]. If GC contents influence DNA thermostability through the frequencies of specific dinucleotides, we might see positive correlations of Topt with the frequencies of some GC-content or AT-content-related dinucleotides. Referring to [67], we calculated the dinucleotide frequencies of the 681 bacterial genomes and the 155 archaeal genomes. In bacteria, no significant correlations were observed between Topt and the frequency of any dinucleotides (Additional file 1: Table S21). In archaea, only the frequency of $\mathrm{AG}(\mathrm{CT})$ is positively correlated with Topt (BM model, slope $=0.002$, $P=0.004)$. This dinucleotide is not related to GC content.

We also performed multiple PGLS regression to separate archaea and bacteria as a new variable. From the dataset of 681 bacteria and 155 archaea, a scaled phylogenetic tree including 415 bacteria and 119 archaea was retrieved from TimeTree [68]. GC content was the dependent variable in this regression, while the Topt and the phylogenetic domain were the two independent variables. Bacteria and Archaea were assigned to 0 and 1 . PGLS regression of only two variables (GC content and Topt) was also performed as a control. Pagel's lambda model had the lowest AIC values in both regressions, so we present the results of this model in Additional file 1: Table S22. The slope of the domain is not statistically significant $(P>0.220$ for all cases), and the adding of this variable did not change the relationship between GC content and Topt (Additional file 1: Table S23).

\section{(See figure on next page.)}

Fig. 4 Nonlinearity in the relationship between prokaryotic optimal growth temperature and GC contents. It was estimated using the generalized additive mixed model (GAMM) by adjusting the genus as a random effect. The dataset including 836 prokaryotes (681 bacteria and 155 archaea) was used in this analysis. The 5 S rRNA genes were not annotated in 60 genomes, so the analysis of the 5 S rRNA has a sample size of 776. The effective degrees of freedom (edf) proxy for nonlinearity in the relationships. We presented the relationships of optimal growth temperature with the GC contents of the whole genome, fourfold degenerate sites, tRNA, $5 S$ rRNA, 16S rRNA, and 235 rRNA as (A), (B), (C), (D), (E), and (F) in this figure and those of the protein-coding sequences and the non-coding DNA were deposited in Additional file 3: Fig. S1. The significance values of the results presented in $(\mathbf{A}) \sim(\mathbf{E})$ are $P=10^{-4}, 8 \times 10^{-7}, 2 \times 10^{-16}, 2 \times 10^{-16}, 2 \times 10^{-16}$, and $2 \times 10^{-16}$, respectively 

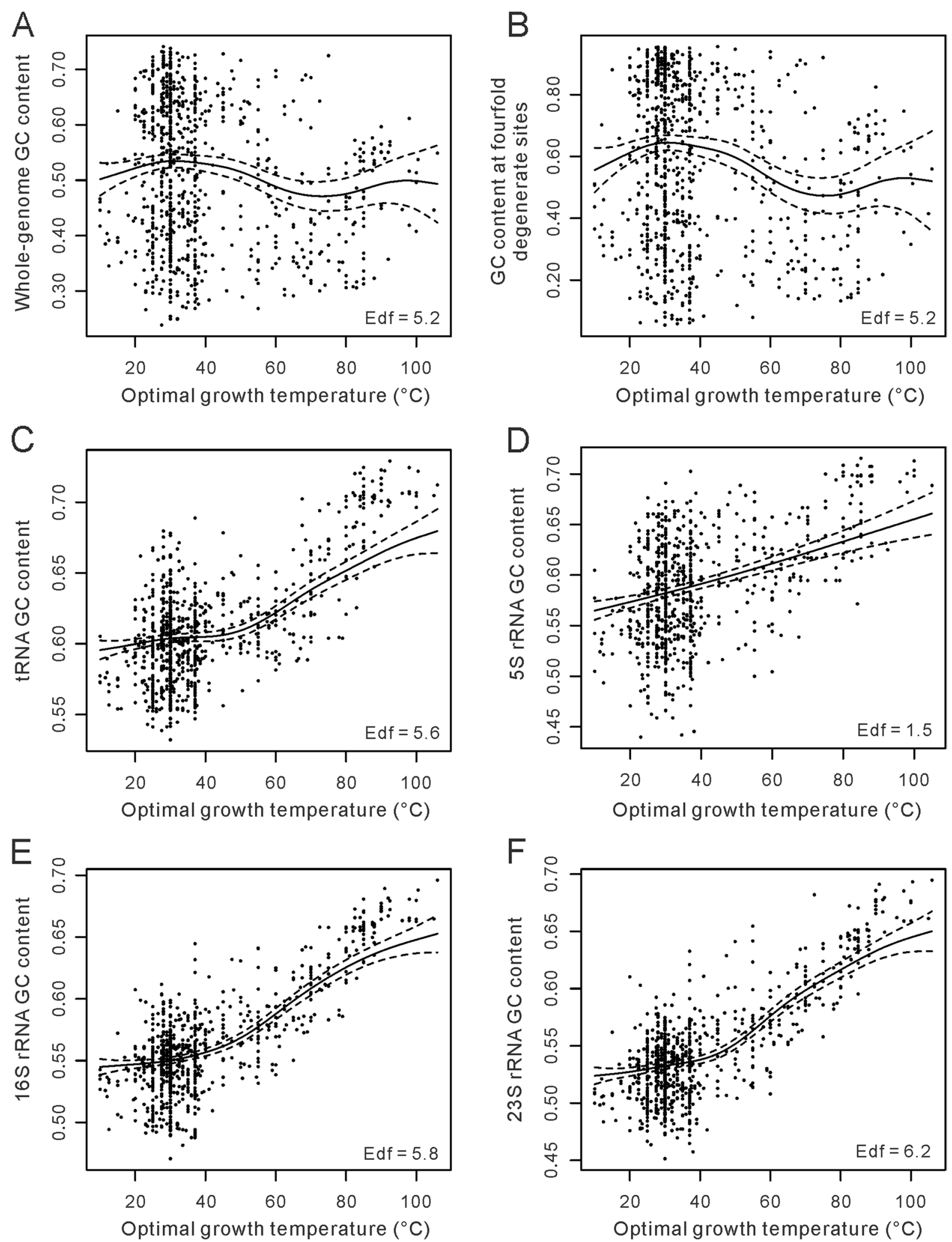

Fig. 4 (See legend on previous page.) 
Similarly, we examined whether the presence and absence of plasmid affect the relationship between GC content and Topt. As shown in (Additional file 1: Table S24), the presence and absence of plasmid is not a statistically significant variable to the evolution of GC content ( $P>0.641$ for all cases). In addition, the relationship between GC content and Topt was not affected by the presence of the second variable.

\section{Discussion}

The GC pairs are thermally more stable than AT pairs in DNA double helix and structural RNAs [23]. However, this difference is not necessarily a strong enough force to shape the evolution of GC content. As RNA structures are more sensitive to temperature elevation than DNA double helix, the growth temperature is expected to have a more substantial effect in shaping the GC content evolution of the structural RNA genes than in shaping the genomic GC content evolution. Positive correlations between growth temperature and the GC content of structural RNA genes have been repeatedly observed in various prokaryotic studies [22, 27, 39-43]. However, there was a long debate on the correlation between growth temperature and genomic GC content. Benefitting from a new manual-curated dataset of prokaryotic growth temperature [39], we performed a phylogenetic comparative analysis with a much larger sample than previous studies $[27,30]$. In 681 bacteria, the genomic GC contents, $G_{w}, G C_{p}, G C_{4}$, and $G_{\text {non }}$, are all positively correlated with growth temperatures, Tmax and Topt. However, in 155 archaea, there are no significant correlations. Then, we resampled 155 bacteria from the 682 bacteria for 1000 rounds. The significant positive correlations between genomic GC contents and growth temperatures disappeared in most cases. The resampling analysis indicates that the small sample sizes of the previous analyses [27] might lead to the lack of significant correlations. It is easy to increase the sample size several times if accurate phylogenetic relationships [56] are not considered in the analysis. As shown in Table 1, we found that both growth temperatures and GC contents exhibit strong phylogenetic signals. Overlooking the effect of common ancestors would severely affect the accuracy of the results [47].

Our resampling analysis indicates that the lack of significant correlations in the 155 samples of archaea might result from the small number of effective samples. Then, we expanded the sample size to 303 archaea by including the GC contents of incompletely assembled genomes (Fig. 3). A positive correlation between $\mathrm{GC}_{\mathrm{w}}$ and Topt in Archaea appears, especially after excluding the halophilic archaea. The halophilic archaea have much higher GC content than other archaea of similar growth temperature, probably because of the intense UV irradiation they have to experience [59]. This result indicates that the effect of temperatures on the GC content evolution is not strong and could be easily overwhelmed by other evolutionary forces. By the same logic, we suspect that other exceptions to the positive correlation between GC content and growth temperature might have experienced some other more vital evolutionary forces shaping GC content in evolution. For example, within the hyperthermophilic genus Thermococcus (Topt ranging from 75 to $89^{\circ} \mathrm{C}$ ), the $\mathrm{GC}_{\mathrm{w}}$ ranges from 40.2 to $58 \%$ [39]. The low-GC-content species in this genus have small genome sizes. Their low GC content might be explained by the reduced efficiency of DNA repair resulting from genome reduction and losses of DNA repairing genes [4, 69-72]. In addition, GC pairs are not always more stable than AT pairs. In the presence of some ions, AT pairs become more stable than GC pairs [73]. In special environmental or physiological conditions that accumulate such ions, AT-rich sequences would be more stable than GC-rich sequences, and the correlation between GC content and growth temperature would be overturned.

Besides adaptive explanations, nonadaptive processes may be explored in the future. In two ecologically distinct groups of bacteria, intracellular symbionts (including mitochondria) and marine bacterioplankton, increased AT contents are accompanied by genome reduction and gene losses (especially the losses of DNA repair genes like mut $Y$ genes) $[4,69-72]$. If most DNA damages tend to decrease GC content, as suggested by some previous studies [74, 75], many DNA repairing genes would counter such effects or even increase GC content as documented in gene conversions [10, 17]. Heat stress can lead to various DNA damages from deaminated cytosine, 8-oxoguanine, to single- and double-stranded DNA breaks [76, 77]. Together with the sensitivity of macromolecular stability to increased temperature, thermophiles experienced a strong selective force for low mutation rates $[78,79]$ and efficient DNA repair systems. We propose that an increase of DNA repair efficiency associated with the increasing growth temperature, or a decrease of DNA repair efficiency associated with the decreasing growth temperature, might shape the evolution of GC content evolution like that happens in intracellular symbionts and marine bacterioplankton.

A recent study suggests that sequential amino acid substitutions are involved in the thermal adaptation in the archaeal order Methanococcales and revealed arginine as the most favored amino acid [80]. As six GC-rich codons encode the arginine, the thermal adaptation at the proteomic level would affect the evolution of genomic GC content. Because the 4-fold degenerate sites are free from the evolutionary forces coming from the natural selection 
acting on protein sequences, our observations of similar correlations of $\mathrm{GC}_{\mathrm{w}}, \mathrm{GC}_{\mathrm{p}}$, and $\mathrm{GC}_{4}$ with growth temperature indicate that the nucleotide composition evolved independently in bacterial adaptation to high temperatures.

As the frequent gain and loss of plasmids, the plasmid DNAs could be regarded as accessory genomes. Because of the high turnover rates of plasmids and accessory genes in prokaryotic evolution, we could regard them as new immigrants, as opposed to the natives for the chromosomes and core genes. Although the core genes and even the ribosomal RNA genes may occasionally be transferred across different prokaryotic lineages [81, 82], the fitness cost of inter-species replacement of homologous sequences [83] restricts the frequency of the core genes. Genes performing essential informational tasks in the cell are less frequently transferred across lineages [84, 85]. Our phylogenetic correlation analysis showed positive correlations between GC contents and growth temperatures in chromosomes, core genes, plasmids, and accessory genes. Also, there is no sharp difference in the correlations between the new immigrants and the natives. In large-scale analyses of horizontal gene transfer in prokaryotes, GC-content similarity between donor and recipient was found to be the factor, or one of the factors, governing the compatibility of the new immigrants in new hosts $[86,87]$. The effect of promoter GC content on the expression of the new immigrants was suggested to be the underlying mechanism governing the compatibility [88]. Here, we suggest that the temperature-associated structural stabilities, including the stability of DNA double helix, the stability of the transient DNA-RNA duplex during transcription, and maybe the stability of the possible secondary structures of mature mRNA [1], might be another nonexclusive factor governing the compatibility. The new immigrants compatible with the host should have GC contents adapted to the host's growth temperature.

A previous serial transfer experiment seems to be contradictory to our results. Increased genomic GC content was not observed in the bacterium $P$. multocida after 14,400 generations of increasing temperature from $37^{\circ} \mathrm{C}$ to $45^{\circ} \mathrm{C}$ [28]. Although we observed a positive correlation between genomic GC content and growth temperature, we do not think a small increment in GC content, resulting from either a GC-biased mutator or integration of a GC-rich exogenous sequence, would bring a great advantage to the host organism. Most likely, it is just a slight advantage. According to the population genetic theory, the slightly beneficial mutants are efficiently selected only when they are in a large population. The experimental evolution generally involves severe, periodic reductions in population size, and the bottleneck effect dramatically reduces the fixation probability of beneficial mutations [89]. As we see, large-scale statistical analysis has the advantage of revealing slightly beneficial traits.

Musto et al. [30] emphasize that the growth temperature can be the only influencing factor in GC content evolution only when closely related species are compared. Our pairwise comparison of neighboring branches with different ranks of growth temperature (Fig. 1) gave the same conclusion as our PGLS analyses. We agree that many factors influence GC content evolution, and the positive relationship between growth temperature and GC content is statistically significant. In the 273 pairs of bacteria, there are 153 pairs where high growth temperature ranks have higher GC contents and 119 pairs with the opposite pattern.

Mahajan and Agashe [3] and the present study found that the evolutionary rates of GC content and growth temperature have occasional jumps assumed in the Lévy jumps model [57]. As shown in Fig. 2, the jump-ups and jump-downs of GC content are significantly correlated with changes in growth temperature and vice versa. It should be emphasized that not all increases in growth temperature were accompanied by increases in GC content. There are just statistically significant correlations $(P<0.05)$.

Some dinucleotides could significantly enhance the stability of double-strand DNA [64-66]. To examine whether the effect of some dinucleotides underlies the positive correlation between GC content and growth temperature, we examined the relationship between Topt and the frequencies of dinucleotides. Unfortunately, no GC-content-altering dinucleotides meet the expectation.

\section{Conclusions}

We should remark that what we observed are weak correlations between genomic GC content and growth temperature. The slopes of the PGLS regressions are generally between $10^{-3}$ and $10^{-4}$. The bacteria rank higher in growth temperature have just $1.43 \%$ more GC (Fig. 1A). Considering the significant difference in the thermoresistence of nucleic acids between in vivo and in vitro [36], we believe that other cellular components mainly contribute to the thermostability of nucleic acids in thermophiles and hyperthermophiles, and the increase of GC content just plays a supplemental role. Moreover, we observed correlations between GC content and growth temperature, suggesting rather than proving the causal effects between the two variables. We should be open to the thermal adaptation hypothesis [23] and other intricate explanations, including nonadaptive ones. This paper aims to end the long-standing debate on the relationship between GC content and growth temperature. Only after establishing the positive correlation could the 
attention of genome biologists be paid to the biological significance of the correlation.

\section{Methods}

We downloaded the prokaryote growth temperatures from the database TEMPURA [39]. This database contains 8639 manual curated prokaryotes (549 archaea and 8090 bacteria). Using the links to the NCBI Taxonomy database [90] and the taxonomy IDs provided by TEMPURA for each prokaryotic strain, we obtained 1110 prokaryotes whose genome assembly levels were labeled as"complete" from the NCBI database [91]. Among them, we found the phylogenetic information for 682 bacteria and 156 archaea from Genome Taxonomy Database [56]. The sequences of these genomes were downloaded from the NCBI genome database [51]. To avoid annotation bias resulting from different methods, all the genomes were re-annotated using the DFAST, version 1.2.11, with its default parameters [92]. In total, we obtained the genome annotations for 836 prokaryotes (681 bacteria and 155 archaea). The GC contents of these prokaryotes were calculated from their genome sequences. The genomes accession numbers and the database links for the 836 prokaryotes are deposited in Additional file 1: Table S25.

We also constructed a large dataset according to their growth temperature qualitatively. First, we divided the 836 prokaryotes (from the database TEMPURA) mentioned above into four categories according to their growth temperature referring to [39]: psychrophiles/ psychrotrophiles (Topt $<20^{\circ} \mathrm{C}$ ), mesophiles $(20 \leq$ Topt $\left.<45^{\circ} \mathrm{C}\right)$, thermophiles $\left(45 \leq\right.$ Topt $\left.<80^{\circ} \mathrm{C}\right)$, and hyperthermophiles $\left(80^{\circ} \mathrm{C} \leq\right.$ Topt $)$. Then, we downloaded the lists of prokaryotes labeled with psychrophiles/psychrotrophiles, mesophiles, thermophiles, or hyperthermophiles from the ProTraits database and the IMG database [54, 55]. Then, we combined the datasets from these three sources (TEMPURA, ProTraits, and IMG) and discarded the overlapping items, the conflicting items, and the items lacking phylogenetic information in the Genome Taxonomy Database [56]. Finally, we obtained a new dataset including 4696 bacteria and 279 archaea (Additional file 1: Table S17). The whole-genome GC contents of these prokaryotes were downloaded directly from the genome report file of the NCBI genome database [93].

As the contrasts between different pairs of terminal tips of the phylogenetic tree are independent, pairwise comparisons between pairs of terminal tips could control the effect of common ancestors. Referring to reference [6], we wrote a script to select pairs of closely related bacteria with different ranks of growth temperature (psychrophiles/psychrotrophiles, mesophiles, thermophiles, and hyperthermophiles). In cases where two or more neighboring tips with the same rank were used to pair with bacteria with another rank, we used the average value of their GC contents to represent the GC content of their internal node. The script is deposited as Additional file 4: Data S2.

The phylogenetic signals $(\lambda)$ of both GC contents and growth temperatures were estimated using the phylosig function of the $\mathrm{R}$ (Version 4.0.3) package phytools (Version 0.7-70) [94]. The PGLS regression was performed using the $\mathrm{R}$ (Version 4.0.3) package phylolm (version 2.6.2) with the default parameters [95].

To avoid false-positive results that might happen in multiple correlation analyses of the same dataset, we controlled the false discovery rate by the BenjaminiHochberg $(\mathrm{BH})$ procedure using the p.adjust function in $\mathrm{R}$ (Version 4.0.3).

Following Mahajan and Agasheand [3], we used the geiger package [96] and the levolution software [57] to simulate our datasets, estimate the branch-specific posterior probabilities of jumps and infer the phylogenetic location of jumps.

The GAMM regressions were performed using the gamm4 function of the package gamm4 (Version 0.2-6, based on package $m g c v$ and package lme4). The formula is:

$$
\mathrm{GC}_{\mathrm{W}} \cdot \sim \cdot \beta_{0}+\cdot \mathrm{s}(\text { Topt }) \cdot+\cdot(1 \text { genus }) \cdot+\cdot \varepsilon
$$

where the $\mathrm{GC}_{\mathrm{w}}$ is the response variable, and the Topt is the explanatory variable, $\mathrm{s}(\mathrm{X})$ means that a smoothing function is used for the explanatory variable. The expression (1|genus) means that a random component was specified with genus as random effects.

\section{Abbreviations \\ A: Adenine; BM: Brownian motion model; C: Cytosine; G: Guanine; $\mathrm{GC}_{165}$ : GC contents of the genes coding $16 \mathrm{~S}$ rRNA; $\mathrm{GC}_{235}$ : $\mathrm{GC}$ contents of the genes coding $23 \mathrm{~S}$ rRNA; $\mathrm{GC}_{3}$ : GC content at the third site of the codons; $\mathrm{GC}_{4}$ : GC contents of the fourfold degenerate sites; $\mathrm{GC}_{55}$ : $\mathrm{GC}$ contents of the genes cod- ing 55 rRNA; $G_{\text {non: }}$ : GC contents of the non-coding DNA (including intergenic sequences and untranslated regions of $\mathrm{mRNA}$ ); $\mathrm{GC}_{\mathrm{p}}$ : $\mathrm{GC}$ contents of the protein-coding sequences; $G_{\text {tRNA }}$ : $G C$ contents of the genes coding tRNAs; $\mathrm{GC}_{w}$ : GC contents of the whole genome; PGLS: Phylogenetic generalized least squares; T:Thymine; Tmax: Maximal growth temperature; Tmin: Minimal growth temperature; Topt: Optimal growth temperature.}

\section{Supplementary Information}

The online version contains supplementary material available at https://doi. org/10.1186/s12864-022-08353-7.

Additional file 1: Supplementary Tables S1-S25.

Additional file 2: Supplementary Data S1. The datasets for the 1000 rounds of resampling.

Additional file 3: Fig. S1. Nonlinearity in the relationship between prokaryotic optimal growth temperature and GC contents. It was estimated using the generalized additive mixed model (GAMM) by adjusting for the genus as a random effect. The dataset including 681 bacterial and 
155 archaeal species was used in this analysis. The effective degrees of freedom (edf) is a proxy for the level of nonlinearity in the relationships. We presented the relationships of optimal growth temperature with the GC contents of protein-coding sequences and non-coding DNA (intergenic sequences and untranslated regions of mRNA that are generally unannotated in prokaryotic genomes) as (A) and (B) in this figure. The significance values of the results presented in $(A)$ and $(B)$ are $P=5 \times 10^{-5}$ and $9 \times 10^{-4}$, respectively.

Additional file 4: Supplementary Data S2. The script used to select pairs of the terminal tips of the phylogenetic tree.

\section{Acknowledgements}

Not applicable.

\section{Authors' contributions}

DKN conceived the study and wrote the manuscript. EZH, XRL, ZLL, and JG performed the data analysis. All authors read, improved, and approved the final manuscript.

\section{Funding}

This work was supported by the National Natural Science Foundation of China (grant number 31671321). The funder had no role in the design of the study or collection, analysis, and interpretation of data or in writing the manuscript.

\section{Availability of data and materials}

All data generated or analyzed during this study are included in this published article and its supplementary information files.

\section{Declarations}

\section{Ethics approval and consent to participate}

Not applicable.

\section{Consent for publication}

Not applicable.

\section{Competing interests}

The authors declare that they have no competing interests.

Received: 3 Auqust 2021 Accepted: 31 January 2022

Published online: 09 February 2022

\section{References}

1. Basak S, Mukhopadhyay P, Gupta SK, Ghosh TC. Genomic adaptation of prokaryotic organisms at high temperature. Bioinformation. 2010;4(8):352-6.

2. Nguyen DT, Wu B, Xiao S, Hao W. Evolution of a record-setting AT-rich genome: indel mutation, recombination, and substitution bias. Genome Biol Evol. 2020;12(12):2344-54.

3. Mahajan S, Agashe D. Evolutionary jumps in bacterial GC content. bioRxiv. 2021; 2021.02.16.431469.

4. Agashe D, Shankar N. The evolution of bacterial DNA base composition. J Exp Zool Part B. 2014;322(7):517-28.

5. Wu H, Zhang Z, Hu S, Yu J. On the molecular mechanism of GC content variation among eubacterial genomes. Biol Direct. 2012;7:2.

6. Aslam S, Lan X-R, Zhang B-W, Chen Z-L, Wang L, Niu D-K. Aerobic prokaryotes do not have higher GC contents than anaerobic prokaryotes, but obligate aerobic prokaryotes have. BMC Evol Biol. 2019;19(1):35.

7. Glemin S, Clement Y, David J, Ressayre A. GC content evolution in coding regions of angiosperm genomes: a unifying hypothesis. Trends Genet. 2014;30(7):263-70.

8. Dietel A-K, Merker H, Kaltenpoth M, Kost C. Selective advantages favour high genomic AT-contents in intracellular elements. PLos Genet. 2019;15(4):e1007778.

9. Foerstner KU, von Mering C, Hooper SD, Bork P. Environments shape the nucleotide composition of genomes. EMBO Rep. 2005;6(12):1208-13.
10. Weissman JL, Fagan WF, Johnson PLF. Linking high GC content to the repair of double strand breaks in prokaryotic genomes. PLoS Genet. 2019;15(11):e1008493.

11. Reichenberger ER, Rosen G, Hershberg U, Hershberg R. Prokaryotic nucleotide composition is shaped by both phylogeny and the environment. Genome Biol Evol. 2015;7(5):1380-9.

12. Šmarda $P$, Bureš $P$, Horová $L$, Leitch IJ, Mucina $L$, Pacini E, et al. Ecological and evolutionary significance of genomic GC content diversity in monocots. Proc Natl Acad Sci USA. 2014;111(39):E4096-E102.

13. Raghavan $\mathrm{R}$, Kelkar YD, Ochman $\mathrm{H}$. A selective force favoring increased $\mathrm{G}+\mathrm{C}$ content in bacterial genes. Proc Natl Acad Sci USA. 2012;109(36):14504-7.

14. Mann S, Chen YPP. Bacterial genomic G plus C composition-eliciting environmental adaptation. Genomics. 2010;95(1):7-15.

15. Hildebrand F, Meyer A, Eyre-Walker A. Evidence of selection upon genomic GC-content in bacteria. PLoS Genet. 2010;6(9):e1001107.

16. Kogay R, Wolf Yl, Koonin EV, Zhaxybayeva O. Selection for reducing energy cost of protein production drives the GC content and amino acid composition bias in gene transfer agents. Mbio. 2020;11(4):13.

17. Lassalle F, Perian S, Bataillon T, Nesme X, Duret L, Daubin V. GC-content evolution in bacterial genomes: the biased gene conversion hypothesis expands. PLoS Genetics. 2015;11:e1004941.

18. Bohlin J, Snipen L, Hardy SP, Kristoffersen AB, Lagesen K, DønsvikT, et al. Analysis of intra-genomic GC content homogeneity within prokaryotes. BMC Genomics. 2010;11(1):464.

19. Rudi K. Environmental shaping of ribosomal RNA nucleotide composition. Microb Ecol. 2009:57(3):469-77.

20. Meyer MM. Revisiting the relationships between genomic $\mathrm{G}$ plus $\mathrm{C}$ content, RNA secondary structures, and optimal growth temperature. J Mol Evol. 2021;89:165-71.

21. Forsdyke DR. Neutralism versus selectionism: Chargaff's second parity rule, revisited. Genetica. 2021;149(2):81-8.

22. Galtier N, Lobry JR. Relationships between genomic G+C content, RNA secondary structures, and optimal growth temperature in prokaryotes. J Mol Evol. 1997;44(6):632-6.

23. Borisova OF, Shchyolkina AK, Chernov BK, Tchurikov NA. Relative stability of AT and GC pairs in parallel DNA duplex formed by a natural sequence. FEBS Lett. 1993;322(3):304-6.

24. Bernardi G, Bernardi G. Compositional constraints and genome evolution J Mol Evol. 1986;24(1):1-11.

25. Winter G, Koch GLE, Hartley BS, Barker DG. The amino acid sequence of the tyrosy1-tRNA synthetase from Bacillus stearothermophilus. Eur J Biochem. 1983;132(2):383-7.

26. Kagawa Y, Nojima H, Nukiwa N, Ishizuka M, Nakajima T, Yasuhara T, et al. High guanine plus cytosine content in the third letter of codons of an extreme thermophile. DNA sequence of the isopropylmalate dehydrogenase of Thermus thermophilus. J Biol Chem. 1984;259(5):2956-60.

27. Hurst LD, Merchant AR. High guanine-cytosine content is not an adaptation to high temperature: a comparative analysis amongst prokaryotes. Proc R Soc B. 2001;268(1466):493-7.

28. Xia X, Wei T, Xie Z, Danchin A. Genomic changes in nucleotide and dinucleotide frequencies in Pasteurella multocida cultured under high temperature. Genetics. 2002;161(4):1385-94.

29. Lambros RJ, Mortimer JR, Forsdyke DR. Optimum growth temperature and the base composition of open reading frames in prokaryotes. Extremophiles. 2003;7(6):443-50.

30. Musto H, Naya H, Zavala A, Romero H, Alvarez-Valin F, Bernardi G. Correlations between genomic $\mathrm{GC}$ levels and optimal growth temperatures in prokaryotes. FEBS Lett. 2004;573(1-3):73-7.

31. Marashi S-A, Ghalanbor Z. Correlations between genomic GC levels and optimal growth temperatures are not 'robust'. Biochem Biophys Res Commun. 2004:325(2):381-3.

32. Basak S, Mandal S, Ghosh TC. Correlations between genomic GC levels and optimal growth temperatures: some comments. Biochem Biophys Res Commun. 2005;327(4):969-70.

33. Musto $H$, Naya H, Zavala A, Romero H, Alvarez-Valin F, Bernardi G. The correlation between genomic $\mathrm{G}+\mathrm{C}$ and optimal growth temperature of prokaryotes is robust: A reply to Marashi and Ghalanbor. Biochem Biophys Res Commun. 2005;330(2):357-60.

34. Wang H-C, Susko E, Roger AJ. On the correlation between genomic $\mathrm{G}+\mathrm{C}$ content and optimal growth temperature in prokaryotes: Data 
quality and confounding factors. Biochem Biophys Res Commun. 2006;342(3):681-4.

35. Musto H, Naya H, Zavala A, Romero H, Alvarez-Valin F, Bernardi G. Genomic GC level, optimal growth temperature, and genome size in prokaryotes. Biochem Biophys Res Commun. 2006;347(1):1-3.

36. Grosjean H, Oshima T. How nucleic acids cope with high temperature: Physiology and Biochemistry of Extremophiles. Washington, DC: American Society of Microbiology; 2007. p. 39-56.

37. Ream RA, Johns GC, Somero GN. Base compositions of genes encoding alpha-actin and lactate dehydrogenase-A from differently adapted vertebrates show no temperature-adaptive variation in $\mathrm{G}+\mathrm{C}$ content. Mol Biol Evol. 2003;20(1):105-10.

38. Zheng $\mathrm{H}, \mathrm{Wu} \mathrm{H}$. Gene-centric association analysis for the correlation between the guanine-cytosine content levels and temperature range conditions of prokaryotic species. BMC Bioinformatics. 2010;11:S7.

39. Sato Y, Okano K, Kimura H, Honda K. TEMPURA: database of growth TEMPeratures of Usual and RAre Prokaryotes. Microbes Environ. 2020;35(3):ME20074.

40. Khachane AN, Timmis KN, dos Santos VAPM. Uracil content of $16 \mathrm{~S}$ rRNA of thermophilic and psychrophilic prokaryotes correlates inversely with their optimal growth temperatures. Nucleic Acids Res. 2005;33(13):4016-22.

41. Kimura H, Sugihara M, Kato K, Hanada S. Selective phylogenetic analysis targeted at $16 \mathrm{~S}$ rRNA genes of thermophiles and hyperthermophiles in deep-subsurface geothermal environments. Appl Environ Microbiol. 2006;72(1):21-7.

42. Kimura H, Ishibashi J-I, Masuda H, Kato K, Hanada S. Selective phylogenetic analysis targeting 165 rRNA genes of hyperthermophilic archaea in the deep-subsurface hot biosphere. Appl Environ Microbiol. 2007:73(7):2110-7.

43. Kimura H, Mori K, Yamanaka T, Ishibashi J-I. Growth temperatures of archaeal communities can be estimated from the guanine-pluscytosine contents of 165 rRNA gene fragments. Env Microbiol Rep. 2013;5(3):468-74.

44. DeSalle R, Riley M. Should networks supplant tree building? Microorganisms. 2020;8(8)

45. Koonin EV. The turbulent network dynamics of microbial evolution and the statistical tree of life. J Mol Evol. 2015;80(5-6):244-50.

46. Blais $C$, Archibald JM. The past, present and future of the tree of life. Curr Biol. 2021;31(7):R314-R21.

47. Felsenstein J. Phylogenies and the comparative method. Am Nat. 1985;125(1):1-15.

48. Symonds MRE, Blomberg SP. A primer on phylogenetic generalised least squares. In: Garamszegi LZ, editor. Modern Phylogenetic Comparative Methods and Their Application in Evolutionary Biology: Concepts and Practice. Berlin: Springer Berlin Heidelberg; 2014. p. 105-30.

49. Rocha EPC, Danchin A. Base composition bias might result from competition for metabolic resources. Trends Genet. 2002;18(6):291-4.

50. Nishida H. Comparative analyses of base compositions, DNA sizes, and dinucleotide frequency profiles in archaeal and bacterial chromosomes and plasmids. Int J Evol Biol. 2012;2012:342482.

51. NCBI Genome database [Available from: ftp://ftp.ncbi.nlm.nih.gov/ genomes/. Accessed 14 Jan 2021.

52. Lindenfors $P$, Revell $L J$, Nunn $C L$. Sexual dimorphism in primate aerobic capacity: a phylogenetic test. J Evol Biol. 2010;23(6):1183-94.

53. Bohlin J, Eldholm V, Pettersson JHO, Brynildsrud O, Snipen L. The nucleotide composition of microbial genomes indicates differential patterns of selection on core and accessory genomes. BMC Genomics. 2017;18:151.

54. Chen I-MA, Chu K, Palaniappan K, Ratner A, Huang J, Huntemann M, et al. The IMG/M data management and analysis system v.6.0: new tools and advanced capabilities. Nucleic Acids Res. 2020:49(D1):D751-D63.

55. Brbić M, Piškorec M, Vidulin V, Kriško A, Šmuc T, Supek F. The landscape of microbial phenotypic traits and associated genes. Nucleic Acids Res. 2016;44(21):10074-90.

56. Parks DH, Chuvochina M, Chaumeil PA, Rinke C, Mussig AJ, Hugenholtz P. A complete domain-to-species taxonomy for Bacteria and Archaea. Nat Biotechnol. 2020;38(9):1079-86.

57. Duchen P, Leuenberger C, Szilagyi SM, Harmon L, Eastman J, Schweizer $\mathrm{M}$, et al. Inference of evolutionary jumps in large phylogenies using Levy processes. Syst Biol. 2017;66(6):950-63.

58. Ludwig W, Viver T, Westram R, Francisco Gago J, Bustos-Caparros E, Knittel K, et al. Release LTP_12_2020, featuring a new ARB alignment and improved 16S rRNA tree for prokaryotic type strains. Syst Appl Microbiol. 2021;44(4):126218.

59. Hescox MA, Carlberg DM. Photoreactivation in Halobacterium cutirubrum. Can J Microbiol. 1972;18(7):981.

60. Loukas A, Kappas I, Abatzopoulos TJ. HaloDom: a new database of halophiles across all life domains. J Biol Res-Thessalon. 2018;25(1):2.

61. Zuur AF, leno EN, Walker N, Saveliev AA, Smith GM. Mixed effects models and extensions in ecology with R. New York: Springer; 2009.

62. Bohlin J, Brynildsrud O, Vesth T, Skjerve E, Ussery DW. Amino acid usage is asymmetrically biased in AT- and GC-rich microbial genomes. PLoS ONE. 2013:8(7):e69878.

63. Zuur AF, leno EN, Walker NJ, Saveliev AA, Smith GM. Things are not always linear; additive modelling. Mixed effects models and extensions in ecology with R. New York: Springer New York; 2009. p. 35-69.

64. Khandelwal G, Bhyravabhotla J. A phenomenological model for predicting melting temperatures of DNA sequences. PLoS ONE. 2010;5(8).

65. Mukherjee S, Kailasam S, Bansal M, Bhattacharyya D. Stacking interactions in RNA and DNA: roll-slide energy hyperspace for ten unique dinucleotide steps. Biopolymers. 2015;103(3):134-47.

66. Delcourt SG, Blake RD. Stacking energies in DNA. J Biol Chem. 1991;266(23):15160-9

67. Karlin S. Global dinucleotide signatures and analysis of genomic heterogeneity. Curr Opin Microbiol. 1998;1(5):598-610.

68. Kumar S, Stecher G, Suleski M, Hedges SB. TimeTree: a resource for timelines, timetrees, and divergence times. Mol Biol Evol. 2017;34(7):1812-9.

69. Kuwahara H, Takaki Y, Shimamura S, Yoshida T, Maeda T, Kunieda T, et al. Loss of genes for DNA recombination and repair in the reductive genome evolution of thioautotrophic symbionts of Calyptogena clams. BMC Evol Biol. 2011;11(1):285.

70. Dufresne A, Garczarek L, Partensky F. Accelerated evolution associated with genome reduction in a free-living prokaryote. Genome Biol. 2005;6(2):R14.

71. Viklund J, Ettema TJG, Andersson SGE. Independent genome reduction and phylogenetic reclassification of the oceanic SAR11 clade. Mol Biol Evol. 2011;29(2):599-615.

72. McCutcheon JP, Moran NA. Extreme genome reduction in symbiotic bacteria. Nat Rev Microbiol. 2012;10(1):13-26.

73. Tateishi-Karimata $\mathrm{H}$, Sugimoto N. A-T base pairs are more stable than $\mathrm{G}-\mathrm{C}$ base pairs in a hydrated ionic liquid. Angew Chem Int Ed. 2012;51(6):1416-9.

74. Hershberg R, Petrov DA. Evidence that mutation is universally biased towards AT in bacteria. PLoS Genet. 2010;6(9):e1001115.

75. Lind PA, Andersson DI. Whole-genome mutational biases in bacteria. Proc Natl Acad Sci USA. 2008;105(46):17878-83.

76. Kantidze OL, Velichko AK, Luzhin AV, Razin SV. Heat stress-induced DNA damage. Acta Naturae. 2016;8(2):75-8.

77. J W Drake a, Baltz RH. The biochemistry of mutagenesis. Annu Rev Biochem. 1976:45(1):11-37.

78. Drake JW. Avoiding dangerous missense: thermophiles display especially low mutation rates. PLoS Genet. 2009;5(6).

79. Friedman R, Drake JW, Hughes AL. Genome-wide patterns of nucleotide substitution reveal stringent functional constraints on the protein sequences of thermophiles. Genetics. 2004;167(3):1507-12.

80. Lecocq M, Groussin M, Gouy M, Brochier-Armanet C. The molecular determinants of thermoadaptation: Methanococcales as a case study. Mol Biol Evol. 2021:38(5):1761-76.

81. Tian R-M, Cai L, Zhang W-P, Cao H-L, Qian P-Y. Rare events of intragenus and intraspecies horizontal transfer of the $16 \mathrm{~S}$ rRNA gene. Genome Biol Evol. 2015;7(8):2310-20.

82. Sato M, Miyazaki K. Phylogenetic network analysis revealed the occurrence of horizontal gene transfer of $16 \mathrm{~S}$ rRNA in the genus Enterobacter. Front Microbiol. 2017;8:10.

83. Bershtein S, Serohijos AWR, Bhattacharyya S, Manhart M, Choi J-M, Mu W, et al. Protein homeostasis imposes a barrier on functional integration of horizontally transferred genes in bacteria. PLoS Genetics. 2015;11(10):e1005612.

84. Kacar B, Garmendia E, Tuncbag N, Andersson DI, Hughes D. Functional constraints on replacing an essential gene with its ancient and modern homologs. mBio. 2017;8(4):e01276-17. 
85. Jain R, Rivera MC, Lake JA. Horizontal gene transfer among genomes: The complexity hypothesis. Proc Natl Acad Sci USA. 1999;96(7):3801-6.

86. Popa O, Hazkani-Covo E, Landan G, Martin W, Dagan T. Directed networks reveal genomic barriers and DNA repair bypasses to lateral gene transfer among prokaryotes. Genome Res. 2011;21(4):599-609.

87. Porse A, Schou TS, Munck C, Ellabaan MMH, Sommer MOA. Biochemical mechanisms determine the functional compatibility of heterologous genes. Nat Commun. 2018;9(1):522.

88. Gomes ALC, Johns NI, Yang A, Velez-Cortes F, Smillie CS, Smith MB, et al. Genome and sequence determinants governing the expression of horizontally acquired DNA in bacteria. ISME J. 2020;14(9):2347-57.

89. Wahl LM, Gerrish PJ, Saika-Voivod I. Evaluating the impact of population bottlenecks in experimental evolution. Genetics. 2002;162(2):961-71.

90. Federhen S. The NCBI Taxonomy database. Nucleic Acids Res. 2012;40(D1):D136-D43.

91. Sayers EW, Beck J, Bolton EE, Bourexis D, Brister JR, Canese K, et al. Database resources of the National Center for Biotechnology Information. Nucleic Acids Res. 2021;49(D1):D10-D7.

92. Tanizawa Y, Fujisawa T, Nakamura Y. DFAST: a flexible prokaryotic genome annotation pipeline for faster genome publication. Bioinformatics. 2018;34(6):1037-9.

93. The genome reports file of NCBI genome database [Available from: https://ftp.ncbi.nlm.nih.gov/genomes/GENOME_REPORTS/prokaryotes. txt. Accessed 1 Apr 2021.

94. Revell LJ. phytools: an R package for phylogenetic comparative biology (and other things). Methods Ecol Evol. 2012;3(2):217-23.

95. Ho LST, Ane C. A linear-time algorithm for Gaussian and non-Gaussian trait evolution models. Syst Biol. 2014;63(3):397-408.

96. Harmon LJ, Weir JT, Brock CD, Glor RE, Challenger W. GEIGER: investigating evolutionary radiations. Bioinformatics. 2008;24(1):129-31.

\section{Publisher's Note}

Springer Nature remains neutral with regard to jurisdictional claims in pub-

lished maps and institutional affiliations.

- fast, convenient online submission

- thorough peer review by experienced researchers in your field

- rapid publication on acceptance

- support for research data, including large and complex data types

- gold Open Access which fosters wider collaboration and increased citations

- maximum visibility for your research: over $100 \mathrm{M}$ website views per year

At BMC, research is always in progress.

Learn more biomedcentral.com/submissions 